\title{
Future Perspectives of Bone Tissue Engineering with Special Emphasis on Extracellular Vesicles
}

\section{Kaur, Sippy}

Springer Nature Switzerland

2019-12-03

Kaur , S , Mannerström , B , Ekstrom , K \& Seppänen-Kaijansinkko , R 2019 , Future

Perspectives of Bone Tissue Engineering with Special Emphasis on Extracellular Vesicles .

in R Seppänen-Kaijansinkko (ed.), Tissue Engineering in Oral and Maxillofacial Surgery . 1.

ed. edn , Springer Nature Switzerland, Gewerbestrasse 11, 6330 Cham, Switzerland, pp.

159-169 . https://doi.org/10.1007/978-3-030-24517-7_11

http://hdl.handle.net/10138/337059

https://doi.org/10.1007/978-3-030-24517-7_11

cc_by_nc

acceptedVersion

Downloaded from Helda, University of Helsinki institutional repository.

This is an electronic reprint of the original article.

This reprint may differ from the original in pagination and typographic detail.

Please cite the original version. 


\section{Future perspectives}

Sippy Kaur ${ }^{1}$, Bettina Mannerström ${ }^{1}$, Karin Ekström ${ }^{2}$ and Riitta Seppänen-Kaijansinkko ${ }^{1}$

1) Department of Oral and Maxillofacial Diseases, University of Helsinki and Helsinki University Hospital, Helsinki, Finland.

2) Department of Biomaterials, Institute of Clinical Sciences, Sahlgrenska Academy, University of Gothenburg, Gothenburg, Sweden

Sippy Kaur, Adjunct Professor, $\mathrm{PhD}$

Department of Oral and Maxillofacial Diseases, University of Helsinki and Helsinki University Hospital, PO Box 63, 00014 University of Helsinki, Finland

email:sippy.kaur@helsinki.fi

Bettina Mannerström, Adjunct Professor, $\mathrm{PhD}$

Department of Oral and Maxillofacial Diseases, University of Helsinki and Helsinki University Hospital, PO Box 63, 00014 University of Helsinki, Finland

email: bettina.mannerstrom@helsinki.fi

Riitta Seppänen-Kaijansinkko, Professor, MD, DDS, $\mathrm{PhD}$

Department of Oral and Maxillofacial Diseases, University of Helsinki and Helsinki University Hospital, PO Box 41, 00014 University of Helsinki, Finland

email: riitta.seppanen-kaijansinkko@helsinki.fi

Karin Ekström, $\mathrm{PhD}$

Department of Biomaterials, Institute of Clinical Sciences, Sahlgrenska Academy, University of Gothenburg, Box 412, 40530 Gothenburg, Sweden

email: karin.ekstrom@biomaterials.gu.se

Tissue engineering therapies to repair or regenerate tissues are based on cells, genes, growth factors, and scaffolds. Currently, bone tissue engineering based on mesenchymal stem cells (MSCs), an osteoinductive scaffold and potentially also a growth factor are applied as a promising strategy for restoring critical-size bone defects and accelerating bone regeneration ${ }^{1-3}$. This cell based approach has several limitations, including time-consuming cell culturing in addition to low homing and survival rates of the transplanted cells ${ }^{4}$ Moreover, recent studies have demonstrated that therapeutic effects of MSCs in tissue engineering are facilitated via paracrine mechanisms ${ }^{5,6}$ exerted by the cells rather than the cells themselves forming new tissue. Therefore cell-free EV based therapy appears to 
be a promising strategy for bone tissue engineering, as EV-based therapy in contrast with stem cell transplantation has several advantages, such as high stability, low immunogenicity ${ }^{7}$ and circumventing complications related with cell transplantation, such as embolization. A paradigm shift in the field of bone tissue engineering is beginning to emerge with stem derived EV based therapy.

EVs are diverse nano-sized bilayer membranous vesicles which are mainly responsible for mediating local and systemic responses (Figure 1). They are secreted by most cell types and are found in biological fluids such as saliva, urine, nasal and bronchial lavage fluid, amniotic fluid, breast milk, plasma, serum and seminal fluid ${ }^{8}$ (Figure 2). As EVs are known to be involved in both physiological as well as pathological processes, interest in their biological roles and its clinical application is expanding ${ }^{9}$ The International Society for Extracellular Vesicles (ISEV), responsible for establishing guidelines for EV research, has suggested the term EV for all the membranous vesicles (exosomes, microvesicles, apoptotic bodies, outer membrane vesicles etc.) released by both prokaryotic and eucaroytic cells. All these vesicles have their own specific biogenesis pathways, size, cargo sorting mechanisms and biological function. ${ }^{8}$

Depending on their cell of origin, EVs contain complex bioactive cargo including proteins, mRNAs, miRNAs, DNAs and lipids. Even though the composition of EV protein is different among cell types, certain proteins, such as the tetraspanins CD9, CD63, and CD81 and proteins from the endosomal compartment, Tsg101 and Alix are enriched in EVs, and these proteins in addition to others are used for EV characterization and identification. Data on the nucleic acid, protein and lipid compositions of EVs from various sources is deposited in the database such as Vesiclepedia (www.microvesicles.org) and EVpedia (http://www.evpedia.info). Stem cell derived EVs are reported to show regenerative effects in different disease models, such as in myocardial ischemia, acute kidney injury, neurological disorders, and wound healing ${ }^{10}$ (Table 1). Thus, in-depth 
investigation on EV cargo could provide insights into the multiple mechanistic pathways involved in the EV mediated regenerative effects, and future approaches for the treatment of diseases.

MSCs are efficient producers of EVs and by delivery of bioactive molecules the EVs have been shown to mimic the therapeutic effects of MSCs. ${ }^{11} \mathrm{MSC}-\mathrm{EV}$ s have also been shown to play important roles in various physiological activities such as immunomodulation, tumorigenesis, angiogenesis, and wound healing. ${ }^{12-14}$ Specifically, MSC-derived EVs inhibit immune reactions in a similar fashion as MSCs, through reduction of inflammatory cytokines and increasing of anti-inflammatory responses ${ }^{15}$. Mechanisms for this mode of action is still not clearly understood. In the study where stem cells and their EVs were studied in parallel, EVs treatment showed similar or even superior therapeutic capacity. ${ }^{16}$

Besides the EVs quality control aspect, another highly important criteria for application of EV therapies is the sufficient amount of EVs. Among different sources of MSCs, adipose derived stem cells are considered abundant and easily accessible source of cells, which can produce scalable amounts of EVs. For tissue engineering applications, EVs from stem cells have shown to have several inherent advantages, such as a) showing expression of several adhesion molecules such as integrins ${ }^{17}$ also binding ability to matrix proteins such as type I collagen and fibronectin ${ }^{18}$; b) possessing potent pro-angiogenic capacity both in vitro and vivo, through enrichment in angiogenesis-related growth factors, mRNAs and miRNAs ${ }^{19,20}$; c) ability to induce osteogenesis, by communication between mineralizing osteoblasts and stromal cells in the bone microenvironment; d) ability to be manipulated, to become enriched with eg. mRNAs, miRNAs or other biomolecules that favor tissue regeneration. Current research highlights that MSC-EVs play important roles in angiogenesis, wound healing, regulate osteoblast activity and differentiation and also promote bone regeneration in vivo ${ }^{22-24}$. While the effects of MSC-derived EVs on bone regeneration are not yet clarified, evidence points towards 
their promoting effect on osteogenesis being due to the a) protective effect reducing apoptosis in necrotic environment ${ }^{25}$; b) induction of angiogenesis to promote vascularization; c) osteoinductive effect to directly promote the osteogenic differentiation of $\mathrm{MSCs}^{26}$. Application of EVs for the treatment of osteochondral and bone-related diseases are shown in table 2. Source of EVs for these diseases were stem cells from various sources such as mesenchymal, synovial, bone marrow and embryonic stem cells.

In a study by Martins et al, concluded that irrespective of their parent cell type or osteogenic induction method, ${ }^{27,28} \mathrm{EVs}$ in vitro can only promote, rather than complete the process of osteoblastogenesis and also displayed strong proliferative, migrative and chemotactic effects. Additionally, only brief osteoinductive stimulation was needed to produce EVs with osteoinductive capacity which significantly promoted the osteogenesis, which was verified by mineralized nodules, and the gene expression of osteogenic genes such as RUNX2, ALP, and COL1A1. Since the osteoinductive effect was not increased by extended osteogenic stimulation, the results point towards briefly osteoinduced EVs having capacity to be further developed into clinically applicable alternative tissue engineering to repair bone defects.

An important issue for the use of EVs in the clinic is the mode of administration. Optimal scaffold for EV based bone tissue engineering should be biocompatible, provide temporary physical support, and most importantly, having ability of releasing EVs in a controlled manner to ensure their sufficient duration required to achieve the functional effect. Recently it was demonstrated ${ }^{29,30}$ that EVs immobilized on PLGA/pD (polylactic-co-glycolic acid/ polydopamine-coating) scaffolds retained the EVs and enabled their slow and local release in mouse critical-sized calvarial defect. The study indicated that PLGA/pD scaffold is a convenient, viable, and efficient carrier for the release of EVs, resulting in significantly more new bone tissue in vivo. 
For successful bone regeneration, vascularization plays a vital role in healing of damaged bone tissue. In a study by Xie et al, scaffolds coated with stem cell EVs were shown to promote bone regeneration in vivo by accelerating vascularization ${ }^{19}$, whereas no major effect was seen on proliferation, apoptosis and osteogenesis, indicating that scaffold modification by EVs provides a promising method to promote vascularization, vital for succesful bone tissue engineering. In another study, bone repair and regeneration in rat model of calvarial bone defect was demonstrated when beta tricalcium phosphate scaffold was functionalized with stem cell-derived $\mathrm{EVs}^{31}$. The underlying mechanism for the bone regeneration may be the activation of endogenous bone marrow stem cells via EVs present in the scaffold. Polyethyleneimine and poly(lactide) scaffolds complexed with stem cells EVs from human gingiva also contributed to regenerating bone defects induced in rat calvaria. ${ }^{32}$ Taken together, all these studies suggests that EVs in combination with scaffolds contribute to osteogenic priming and enhanced vascularization in critical-size bone defects. Therefore, as shown in Figure 3, in the coming years, further research and development of EVs with new or already existing biomaterials will potentially lead to emergence of novel therapeutic alternatives in the field of bone tissue engineering

For the transition of EV-based therapies from animal models to clinical therapy, EV isolation and characterization methods need to be standardized. Currently, there are several methods such ultracentrifugation, density gradient, ultrafiltration, immuno-affinity, precipitation and microfluidics, which are used for EV isolation. Among these, ultracentrifugation is the most widely used method. ${ }^{33}$ For EV characterization, combination of different methods such as particle analysis (Nanosight Tracking Analysis, NTA), Advanced Flow Cytometry, dynamic light scattering (DLS), Western blotting and electron microscopy are most commonly used. NTA determines the particle size distribution and number, Western blotting quantifies the protein expression of EVs and electron microscopy is utilized for visualization of EVs. Other ways to establish the EV dose may be by ELISA to measure concentration of EV markers or by using cell equivalents (donor cell number). 
ISEV recommends that EVs can be stored in $-80 \mathrm{C}$, but the optimal storage conditions of EVs for clinical applications is yet to be determined, as loss of function of EVs after defreezing has been reported $^{34}$. Freeze-drying of EVs could improve their stability at higher temperatures, without significant loss of their biological activities ${ }^{35}$. It is still unclear if all subpopulations of EVs can be freeze-dried by same method and what the maximum shelf-life of the freeze-dried EVs is. For clinical applications, further research is needed to determine the best method for EV isolation, their functional characterization and the optimal storage condition.

EVs have attracted attention in the field of targeted drug delivery and have a demonstrated potential to be used as efficient and functional delivery systems. Compared to synthetic nanoparticles, EVs exhibit important advantages, such as 1) membrane modifications for specific cell targeting, 2) drug loading for targeted therapy, 3) small size enabling them to escape from lung clearance and pass through the blood-brain barrier, 4) potential delivery vehicles as they are easily scaleable to produce large quantities of EVs and would not elicit immune rejection response or adverse effect ${ }^{36}$. Route of EV administration could be intravenous injection, subcutaneous/intravenous, intranasal and in situ injection.

Since the EV cargo contains the information about the pathophysiological conditions of the host cell, they are considered an important tool for biomarker discovery and to monitor the disease status. Therefore genomics, proteomics and lipidomics profiling of EV cargo for the disease in question is fundamental for the detection of new biomarkers. RNAs and proteins in EVs have been found to be useful in monitoring a wide range of diseases. For example, EVs purified from the urine of prostate cancer patients showed elevated levels of prostate cancer antigen-3 (PCA-3), which can be used to monitor the status of the disease ${ }^{37}$. Elevated expression of cancer biomarkers in EVs were also detected in cancers such as gastric cancer, glioblastoma and lung cancer. ${ }^{38,39}$ 
EVs from stem cells as a therapeutics are already entering clinical trials and several trials are ongoing (Figure 4) where EVs are used as a diagonistic tool or biomarker. Clinical application of EVs is yet to be validated as trials are in very early phases; very few studies are undertaken or are currently ongoing as shown in table 3 . Across these studies, a variety of EV isolation and purification methods were applied, which could affect the consistency of the results. In addition to obstacles in EV isolation methods, there remain several other challenges in successful implementation of EVs into clinical use, in particular, detailed characterization of subpopulation EVs, scalable EV production methods to collect uniform EVs and their storage conditions. There are still several unanswered questions before EVs can be exploited fully a novel standardized therapeutic tool.

To receive sufficient amounts of EVs, production scale-up is necessary. This may be performed using bioreactors as well as by stimulation of the donor cells. Cell culturing condition need also to be standardized, since slight changes in the cell culture will affect the release, composition and function of the EVs. Many different EV isolation methods are used, and new novel methods are emerging. They all have their advantages and disadvantages (e.g. high/low yield, high/low purity, largescale/small-scale, short/long working time) and there is no method that is optimal for all different types of experiments. ${ }^{40}$ However, for future isolation of clinical-grade EVs, it is desired to have a reproducible, large-scale method, resulting in high-yield of functional EVs. Furthermore, many parameters including storage temperatures, buffers, repeated freezing-thawing cycles may all affect the EV quality and quantity and thus needs to be evaluated further to find the optimal condition. Furthermore, it is important to note that different EV isolations methods may result in in the isolation of different populations of EVs. It might only be some subtype of EV that is necessary to obtain the desired effect and this will need to be assessed further in specific cases, and methods to isolate specific sup-types of EVs further developed. 
The global market for EV diagnostics and therapeutic companies is projected to grow from $\$ 16.1$ million in 2016 to 111.8 million in $2021^{41}$. Several companies (Aethlon, Exosomess Sciences, Anosys Inc, Capricor Therapeutics Inc, Caris Life Sciences, Codiak Biosciences, Exosomes Diagnostics, Exovita Biosciences, ReNeuron and Systems Biosciences) are conducting research and development that aim to develop EV based therapeutics or diagnostic biomarkers (Table 4). To date, at least 4 companies (ReNeuron, Capricor and Aegle Therapeutics, Codiak Biosciences) are developing commercial use of EVs. Beneficial applications of EVs in cardiac and muscle disease is undertaken by Capricor Inc. ReNeuron Group PLC are focusing on neurological and ischemic conditions. Application of EV-based vaccines in cancer therapy is developed by Anosys Inc.

From a regulatory and medicinal usage perspective, reasons for using MSC-EVs instead of cells are that they have the beneficial effects as the cells but the easier handling and storage, better stability and possibilities to sterilize by filtration (most EVs are $<200 \mathrm{~nm}$ ). Aspects that require develoment before EVs can be applied in the clinic are related to the controlled manufacturing of sufficient amounts of EVs; which includes the cell culture, EV isolation and storage, quantification, determination of the composition and purity/contamination as well as in vitro potency tests ${ }^{10}$. For MSC EVs, a proliferation assay might be suitable since MSC EVs All this will need to be assessed for every batch of EVs that will be later used clinically. EV-based therapeutics will most likely be classified as Biological Medicinal Products and belong to the pharmaceutical class of biologicals (tissue- and cell-based products regulation may be used). Already now, the regulatory framework exist for manufacturing and clinical trials of EVs in Europe, Australia, and United states. A hurdle in EV-based therapeutics may be establishing the Mode of action (MoA), since the EVs consists of a complex composition of molecules, and most likely a combination of molecules is responsible for the MoA. 
Concluding remarks: EVs are novel players in cell communication systems and mediators of horizontal transfer of bioactive cargo in gene regulation. Their molecular composition, function, and targeting mechanisms is still a young research field. Therefore, demanding new high resolution technological advances for large scale standardized GMP-grade production, characterization, storage and safety issues needs to be also addressed for subsequent clinical trails. Due to its biological and regulatory complexity, more extensive research on the application of EVs in clinical and therapeutic advancement are warranted. 
Table 1. EV based approaches used on animal model for the treatment of the different disease (modified from Willis et al, 2017 ${ }^{10}$ )

\begin{tabular}{|c|c|c|}
\hline Disease Model & Animal model & References \\
\hline \multicolumn{3}{|l|}{ Respiratory } \\
\hline $\begin{array}{l}\text { Bronchopulmonary } \\
\text { dysplasia }\end{array}$ & Mouse & 48 \\
\hline Pulmonary hypertension & Mouse & 49,50 \\
\hline Acute lung injury & Mouse & 51 \\
\hline Silicosis & Mouse & 14 \\
\hline Pneumonia & Mouse & 52 \\
\hline \multicolumn{3}{|l|}{ Cardiovascular } \\
\hline Myocardial infarction & Rat & $53-55$ \\
\hline Ischemia/reperfusion & Mouse & 56,57 \\
\hline \multicolumn{3}{|l|}{ Neurological } \\
\hline Traumatic brain injury & Mouse & 58 \\
\hline $\begin{array}{l}\text { Laser-induced retinal } \\
\text { injury }\end{array}$ & Mouse & 59 \\
\hline Optical nerve crush & Rat & 60 \\
\hline Stroke & Rat and Mouse & 61,62 \\
\hline \multicolumn{3}{|l|}{ Musculoskeletal } \\
\hline Cardiotoxin injury & Mouse & 63 \\
\hline \multicolumn{3}{|l|}{ Hepatic } \\
\hline Drug-induced liver injury & Mouse & 64 \\
\hline Liver fibrosis & Mouse & 65 \\
\hline \multicolumn{3}{|l|}{ Gastrointestinal } \\
\hline Colitis & Rat and Mouse & 66,67 \\
\hline \multicolumn{3}{|l|}{ Dermatological } \\
\hline Wound healing & Rat and Mouse & 67,68 \\
\hline \multicolumn{3}{|l|}{ Renal } \\
\hline Ischemia/reperfusion & Rat & 69 \\
\hline Acute kidney injury & Mouse & 70 \\
\hline
\end{tabular}

Table 2: EVs used as therapeutic agents in animal models of osteochondral and bone related therapies

\begin{tabular}{|l|l|l|}
\hline Therapeutic agents & $\begin{array}{l}\text { Animal model/in vitro cell } \\
\text { model }\end{array}$ & References \\
\hline Osteoarthritis & Rat & 71 \\
\hline
\end{tabular}




\begin{tabular}{|l|l|l|}
\hline Endochondral ossification in bone fracture & Mouse & 72 \\
\hline Osteochondral defects & Rat & 31 \\
\hline $\begin{array}{l}\text { protection from cartilage and bone } \\
\text { degradation }\end{array}$ & mouse & 73 \\
\hline Inflammantion in the synovia & Mouse & 74 \\
\hline Rheumatoid arthritis & Mouse & 75 \\
\hline Osteoporosis & Rat & 26 \\
\hline Femoral head necrosis & Rabbit & 30 \\
\hline Bone defects & Rat and mouse & 30,31 \\
\hline Bone regeneration model & Mouse and in vitro & $76-78$ \\
\hline
\end{tabular}

Table 3: EV based clinical trials (modified from Willis et al, 2017 ${ }^{10}$ )

\begin{tabular}{|c|c|c|c|c|}
\hline Disease & Phase & EV source & Status & Reference \\
\hline Melanoma & $\begin{array}{l}\text { I-open } \\
\text { label }\end{array}$ & $\begin{array}{l}\text { Autologous monocyte-derived dendritic } \\
\text { cells }\end{array}$ & Complete & 42 \\
\hline $\begin{array}{l}\text { Non-small cell lung } \\
\text { cancer }\end{array}$ & $\begin{array}{l}\text { I-open } \\
\text { label }\end{array}$ & $\begin{array}{l}\text { Autologous monocyte-derived dendritic } \\
\text { cells }\end{array}$ & Complete & 43 \\
\hline Colon cancer & $\begin{array}{l}\text { I-open } \\
\text { label }\end{array}$ & Autologous ascites & Complete & 44 \\
\hline Colon cancer & $\begin{array}{l}\text { I-open } \\
\text { label }\end{array}$ & Plant based & Ongoing & NCT01294072 \\
\hline Type I diabetes & $\begin{array}{l}\text { I-open } \\
\text { label }\end{array}$ & Allogenic umbical cord blood MSC & Ongoing & NCT02138331 \\
\hline $\begin{array}{l}\text { Non-small cell lung } \\
\text { cancer }\end{array}$ & $\begin{array}{l}\text { II-open } \\
\text { label }\end{array}$ & Tumor cell & Complete & 45 \\
\hline $\begin{array}{l}\text { Wound healing } \\
\text { (Ulcer) }\end{array}$ & $\begin{array}{l}\text { I-open } \\
\text { label }\end{array}$ & Autologous plasma & Enrolling & NCT02565264 \\
\hline $\begin{array}{l}\text { Cerebrovascular } \\
\text { Disorders }\end{array}$ & $\mathrm{I} / \mathrm{II}$ & $\begin{array}{l}\text { Allogenic Mesenchymal Stem Cell } \\
\text { Derived Evs }\end{array}$ & $\begin{array}{l}\text { Not yet } \\
\text { recruiting }\end{array}$ & NCT03384433 \\
\hline $\begin{array}{l}\text { Stage IV Pancreatic } \\
\text { Cancer }\end{array}$ & $\mathrm{I}$ & $\begin{array}{l}\text { Mesenchymal Stromal Cells-derived Evs } \\
\text { with KRAS G12D siRNA }\end{array}$ & $\begin{array}{l}\text { Not yet } \\
\text { recruiting }\end{array}$ & NCT03608631 \\
\hline Macular Holes & $\begin{array}{l}\text { Early } \\
\text { phase I }\end{array}$ & $\begin{array}{l}\text { EVs derived from mesenchymal stem } \\
\text { cells }\end{array}$ & Recruiting & NCT03437759 \\
\hline $\begin{array}{l}\text { Polycystic Ovary } \\
\text { Syndrome }\end{array}$ & NA & Plant EVs & $\begin{array}{l}\text { Not yet } \\
\text { recruiting }\end{array}$ & NCT03493984 \\
\hline $\begin{array}{l}\text { Graft versus host } \\
\text { disease }\end{array}$ & NA & Allogeneic MSC-EVs & Complete & 46 \\
\hline
\end{tabular}

Table 4: List of companies on EV based products and services (modified from Gimona et $\mathrm{al}^{47}$ )

\begin{tabular}{|l|l|l|}
\hline Name of the company & Therapeutic target & Web address \\
\hline Anjarium Biosciences & Broad range of severe diseases & $\underline{\mathrm{http}: / / \text { anjarium.com/ }}$ \\
\hline Aposcience AG & $\begin{array}{l}\text { Stroke, spinal cord injury, skin lesions, acute } \\
\text { and chronic myocardial infarction }\end{array}$ & $\begin{array}{l}\text { http://www.aposcience.at/the } \\
\text { secretome-company/ }\end{array}$ \\
\hline Capricor Therapeutics & Cardiovascular and non-cardiovascular diseases & $\underline{\text { http://capricor.com/ }}$ \\
\hline
\end{tabular}




\begin{tabular}{|l|l|l|}
\hline Codiak Biosciences & Pancreatic cancer & $\underline{\text { http://codiakbio.com/ }}$ \\
\hline Evox Therapeutics & Inflammatory and neurological diseases & $\underline{\text { http://www.evoxtherapeutics.com/ }}$ \\
\hline ExoCyte Therapeutics & Cancer & $\underline{\text { http://exocytetherapeutics.com/ }}$ \\
\hline $\begin{array}{l}\text { Exogenus } \\
\text { Therapeutics }\end{array}$ & Skin lesions & $\underline{\text { http://www.exogenus-t.com/ }}$ \\
\hline Exovita Biosciences & cancers & $\underline{\text { http://exovitabio.com/ }}$ \\
\hline Kimera Labs & $\begin{array}{l}\text { Orthopedic, cosmetic and regenerative } \\
\text { medicine applications }\end{array}$ & $\underline{\text { http://kimeralabs.com/ }}$ \\
\hline ReCyte Therapeutics & Vascular disorders & $\underline{\text { http://recyte.com/ }}$ \\
\hline ReNeuron & Neurologic and ophthalmologic disorders & $\underline{\text { http://reneuron.com/ }}$ \\
\hline $\begin{array}{l}\text { Stemedica Cell } \\
\text { Technologies, Inc. }\end{array}$ & $\begin{array}{l}\text { Cardiovascular diseases, traumatic brain injury } \\
\text { and alzheimers disease }\end{array}$ & $\underline{\text { http://stemedica.com/ }}$ \\
\hline ZenBio & Skin lesions & $\underline{\text { http://www.zen-bio.com/ }}$ \\
\hline
\end{tabular}
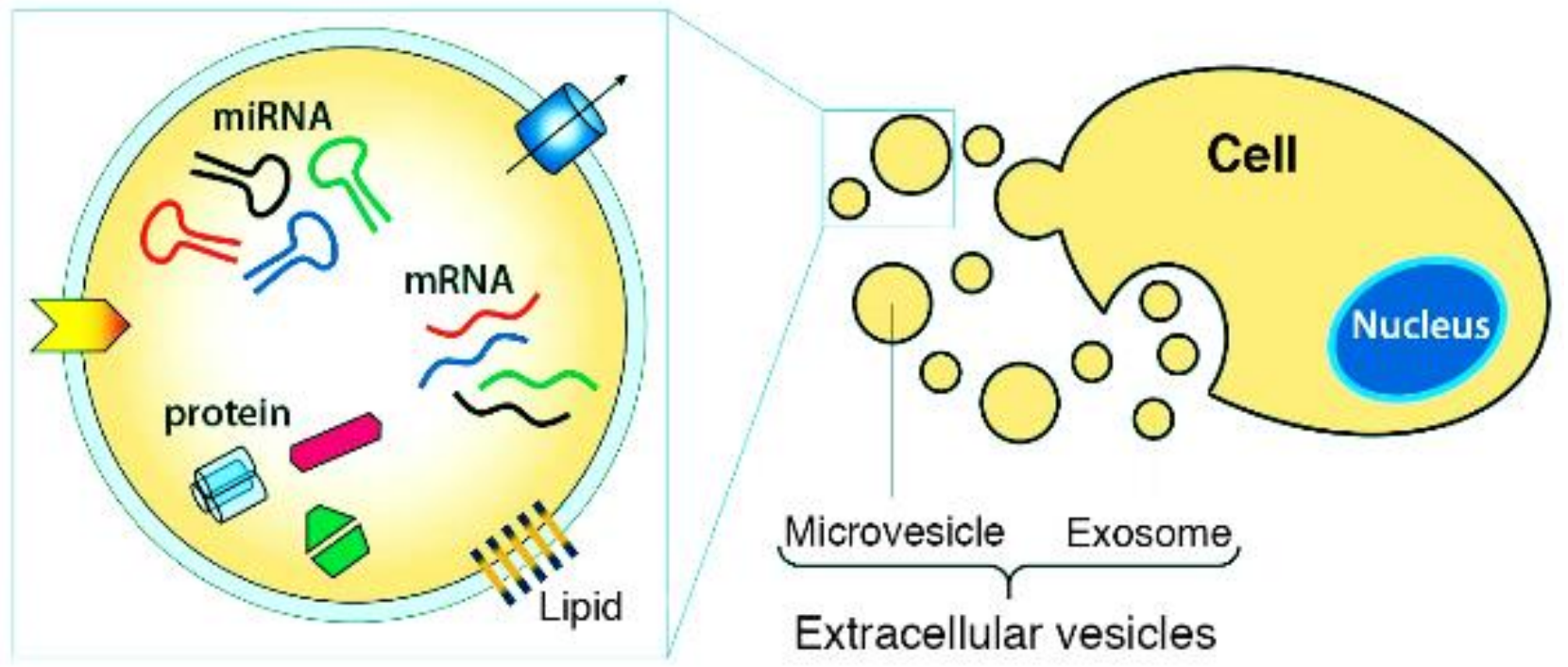

Figure 1: EV anatomy. Nano-sized membrane bound EV released from the parent cell. Cargo of EV includes protein (both cytosolic and membrane bound), lipids and RNA molecules. Figure modified from (http://www.bioprocessintl.com/manufacturing/cell-therapies/extracellular-vesiclescommercial-potential-as-byproducts-of-cell-manufacturing-for-research-and-therapeutic-use/) 


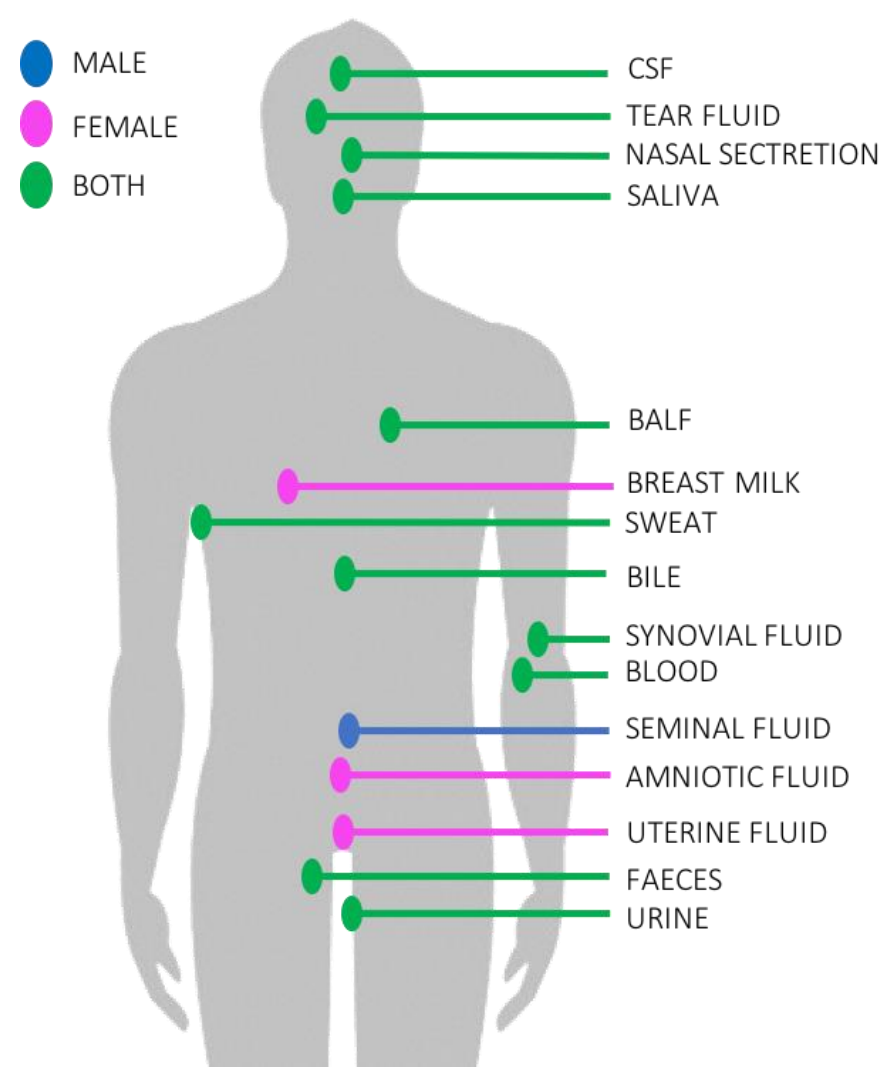

Figure 2. Schematic of in vivo-derived EVs isolated from body fluids. Cells from different human tissues of the body communicate through the secretion of EVs into proximal body fluids. EVs contain proteins, lipids and RNA molecules that may affect the physiology of cells bathed in or lining these body fluids. Highlighted here are the body fluids where EVs have been identified and their possible cellular origin. Pink spots represent body fluids, which are only present in females. Green spots represent body fluids, which are only present in male. Yellow spots represent body fluids present in both female and male. $\mathrm{CSF}=$ cerebrospinal fluid; $\mathrm{BALF}=$ Broncho alveolar lavage fluid. 


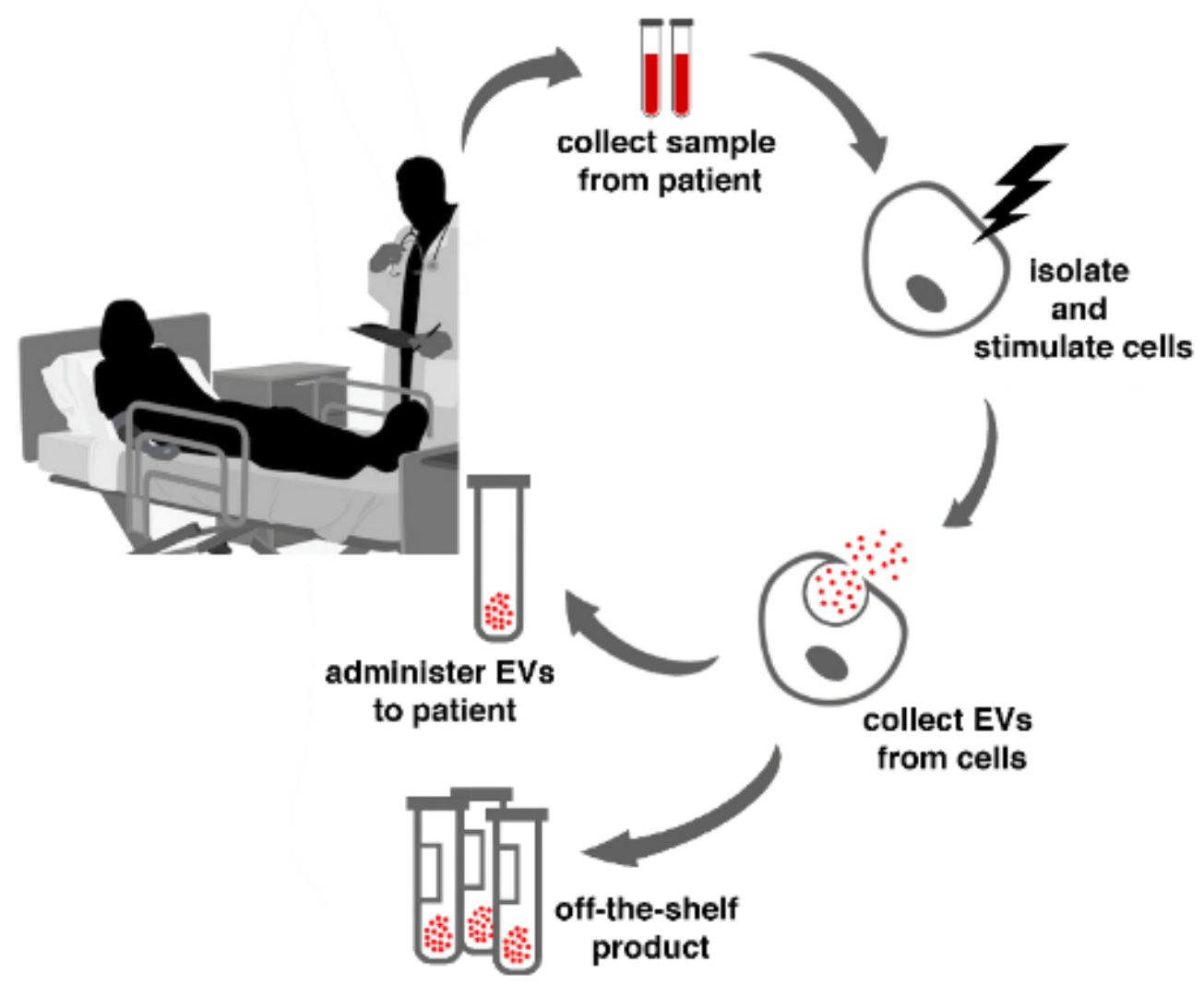

Figure 3: Stem cell EVs for clinical applications. In future, EVs produced under quality controlled regulatory procedures will be stored as off-the shelf product to be used for specific applications. This picture is modified from http://2015.igem.org/Team:NJU-China

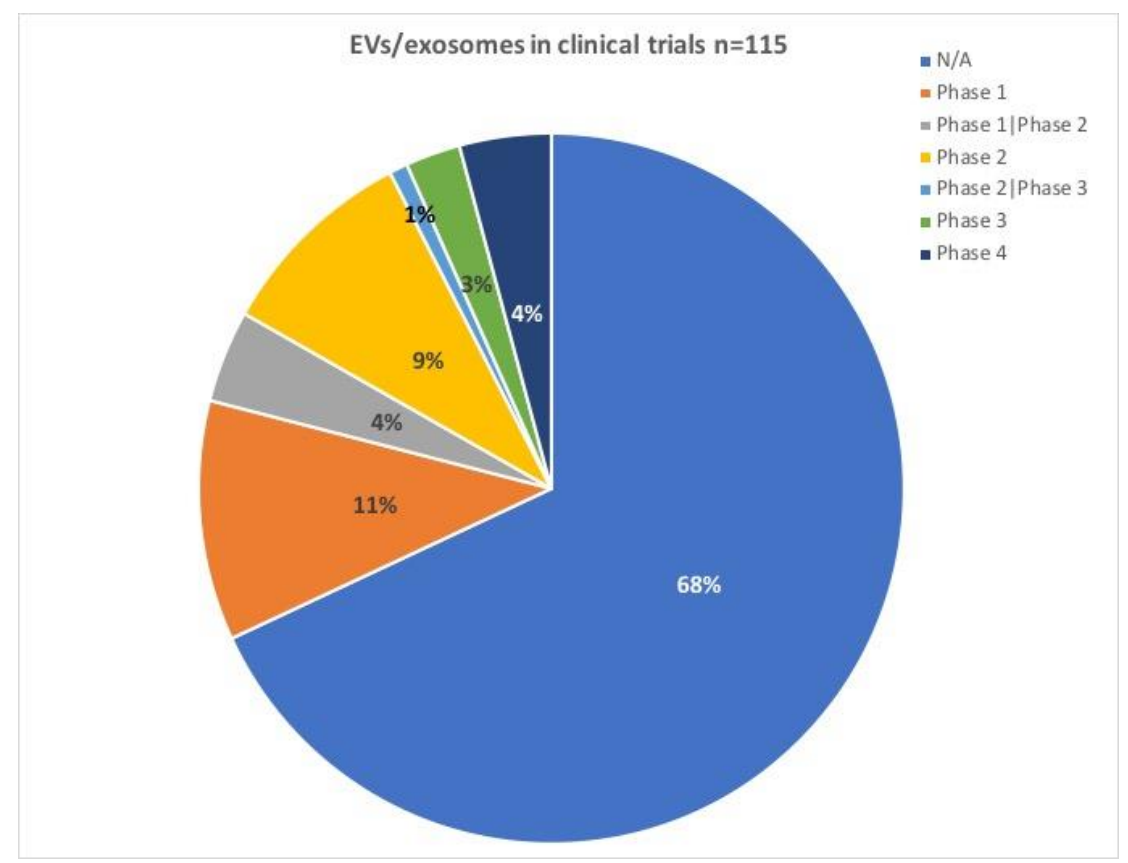

Figure 4: Clinical trials in different phases with administering of EVs/exosomes, according to clinicaltrials.gov 7.8.2018 


\section{References:}

1. Huey DJ, Hu JC, Athanasiou KA. Unlike bone, cartilage regeneration remains elusive. Science. 2012;338(6109):917-921. doi: 10.1126/science.1222454 [doi].

2. Bianco P, Cao X, Frenette PS, et al. The meaning, the sense and the significance: Translating the science of mesenchymal stem cells into medicine. Nat Med.2013;19(1):35-42. doi: 10.1038/nm.3028 [doi].

3. Fennema EM, Tchang LAH, Yuan H, et al. Ectopic bone formation by aggregated mesenchymal stem cells from bone marrow and adipose tissue: A comparative study. J Tissue Eng Regen Med. 2018;12(1):e150-e158. doi: 10.1002/term.2453 [doi].

4. Eggenhofer E, Luk F, Dahlke MH, Hoogduijn MJ. The life and fate of mesenchymal stem cells. Front Immunol. 2014;5:148. doi: 10.3389/fimmu.2014.00148 [doi].

5. Gnecchi M, He H, Liang OD, et al. Paracrine action accounts for marked protection of ischemic heart by akt-modified mesenchymal stem cells. Nat Med. 2005;11(4):367-368. doi: nm0405-367 [pii].

6. Timmers L, Lim SK, Arslan F, et al. Reduction of myocardial infarct size by human mesenchymal stem cell conditioned medium. Stem Cell Res. 2007;1(2):129-137. doi: 10.1016/j.scr.2008.02.002 [doi].

7. El Andaloussi S, Lakhal S, Mager I, Wood MJ. Exosomes for targeted siRNA delivery across biological barriers. Adv Drug Deliv Rev. 2013;65(3):391-397. doi: 10.1016/j.addr.2012.08.008 [doi].

8. Yanez-Mo M, Siljander PR, Andreu Z, et al. Biological properties of extracellular vesicles and their physiological functions. J Extracell Vesicles. 2015;4:27066. doi: 10.3402/jev.v4.27066 [doi]. 
9. Vader P, Breakefield XO, Wood MJ. Extracellular vesicles: Emerging targets for cancer therapy. Trends Mol Med. 2014;20(7):385-393. doi: 10.1016/j.molmed.2014.03.002 [doi].

10. Willis GR, Kourembanas S, Mitsialis SA. Toward exosome-based therapeutics: Isolation, heterogeneity, and fit-for-purpose potency. Front Cardiovasc Med. 2017;4:63. doi: 10.3389/fcvm.2017.00063 [doi].

11. Fatima F, Ekstrom K, Nazarenko I, et al. Non-coding RNAs in mesenchymal stem cell-derived extracellular vesicles: Deciphering regulatory roles in stem cell potency, inflammatory resolve, and tissue regeneration. Front Genet. 2017;8:161. doi: 10.3389/fgene.2017.00161 [doi].

12. Hu L, Wang J, Zhou X, et al. Exosomes derived from human adipose mensenchymal stem cells accelerates cutaneous wound healing via optimizing the characteristics of fibroblasts. Sci Rep. 2016;6:32993. doi: 10.1038/srep32993 [doi].

13. Kaur S, Singh SP, Elkahloun AG, Wu W, Abu-Asab MS, Roberts DD. CD47-dependent immunomodulatory and angiogenic activities of extracellular vesicles produced by T cells. Matrix Biol. 2014;37:49-59. doi: 10.1016/j.matbio.2014.05.007 [doi].

14. Phinney DG, Pittenger MF. Concise review: MSC-derived exosomes for cell-free therapy. Stem Cells. 2017;35(4):851-858. doi: 10.1002/stem.2575 [doi].

15. Zhou Y, Day A, Haykal S, Keating A, Waddell TK. Mesenchymal stromal cells augment CD4+ and CD8+ T-cell proliferation through a CCL2 pathway. Cytotherapy. 2013;15(10):1195-1207. doi: 10.1016/j.jcyt.2013.05.009 [doi].

16. Aslam M, Baveja R, Liang OD, et al. Bone marrow stromal cells attenuate lung injury in a murine model of neonatal chronic lung disease. Am J Respir Crit Care Med. 2009;180(11):11221130. doi: 10.1164/rccm.200902-0242OC [doi]. 
17. Bruno S, Grange C, Deregibus MC, et al. Mesenchymal stem cell-derived microvesicles protect against acute tubular injury. J Am Soc Nephrol. 2009;20(5):1053-1067. doi:

10.1681/ASN.2008070798 [doi].

18. Narayanan R, Huang CC, Ravindran S. Hijacking the cellular mail: Exosome mediated differentiation of mesenchymal stem cells. Stem Cells Int. 2016;2016:3808674. doi: $10.1155 / 2016 / 3808674$ [doi].

19. Xie H, Wang Z, Zhang L, et al. Extracellular vesicle-functionalized decalcified bone matrix scaffolds with enhanced pro-angiogenic and pro-bone regeneration activities. Sci Rep. 2017;7:45622. doi: 10.1038/srep45622 [doi].

20. Chen J, Liu Z, Hong MM, et al. Proangiogenic compositions of microvesicles derived from human umbilical cord mesenchymal stem cells. PLoS One. 2014;9(12):e115316. doi: 10.1371/journal.pone.0115316 [doi].

21. Gebraad A, Kornilov R, Kaur S, et al. Monocyte-derived extracellular vesicles stimulate cytokine secretion and gene expression of matrix metalloproteinases by mesenchymal stem/stromal cells. FEBS J. 2018;285(12):2337-2359. doi: 10.1111/febs.14485 [doi].

22. Hu L, Wang J, Zhou X, et al. Exosomes derived from human adipose mensenchymal stem cells accelerates cutaneous wound healing via optimizing the characteristics of fibroblasts. Sci Rep. 2016;6:32993. doi: 10.1038/srep32993 [doi].

23. Togliatto G, Dentelli P, Gili M, et al. Obesity reduces the pro-angiogenic potential of adipose tissue stem cell-derived extracellular vesicles (EVs) by impairing miR-126 content: Impact on clinical applications. Int J Obes (Lond). 2016;40(1):102-111. doi: 10.1038/ijo.2015.123 [doi]. 
24. Qin Y, Wang L, Gao Z, Chen G, Zhang C. Bone marrow stromal/stem cell-derived extracellular vesicles regulate osteoblast activity and differentiation in vitro and promote bone regeneration in vivo. Sci Rep. 2016;6:21961. doi: 10.1038/srep21961 [doi].

25. Liu X, Li Q, Niu X, et al. Exosomes secreted from human-induced pluripotent stem cell-derived mesenchymal stem cells prevent osteonecrosis of the femoral head by promoting angiogenesis. Int $J$ Biol Sci. 2017;13(2):232-244. doi: 10.7150/ijbs.16951 [doi].

26. Qi X, Zhang J, Yuan H, et al. Exosomes secreted by human-induced pluripotent stem cellderived mesenchymal stem cells repair critical-sized bone defects through enhanced angiogenesis and osteogenesis in osteoporotic rats. Int J Biol Sci. 2016;12(7):836-849. doi: 10.7150/ijbs.14809 [doi].

27. Martins M, Ribeiro D, Martins A, Reis RL, Neves NM. Extracellular vesicles derived from osteogenically induced human bone marrow mesenchymal stem cells can modulate lineage commitment. Stem Cell Reports. 2016;6(3):284-291. doi: 10.1016/j.stemcr.2016.01.001 [doi].

28. Li W, Liu Y, Zhang P, et al. Tissue-engineered bone immobilized with human adipose stem cells-derived exosomes promotes bone regeneration. ACS Appl Mater Interfaces. 2018;10(6):52405254. doi: 10.1021/acsami.7b17620 [doi].

29. Qi X, Zhang J, Yuan H, et al. Exosomes secreted by human-induced pluripotent stem cellderived mesenchymal stem cells repair critical-sized bone defects through enhanced angiogenesis and osteogenesis in osteoporotic rats. Int J Biol Sci. 2016;12(7):836-849. doi: 10.7150/ijbs.14809 [doi]. 
30. Li W, Liu Y, Zhang P, et al. Tissue-engineered bone immobilized with human adipose stem cells-derived exosomes promotes bone regeneration. ACS Appl Mater Interfaces. 2018;10(6):52405254. doi: 10.1021/acsami.7b17620 [doi].

31. Zhang J, Liu X, Li H, et al. Exosomes/tricalcium phosphate combination scaffolds can enhance bone regeneration by activating the PI3K/akt signaling pathway. Stem Cell Res Ther. 2016;7(1):136-016-0391-3. doi: 10.1186/s13287-016-0391-3 [doi].

32. Diomede F, Gugliandolo A, Cardelli P, et al. Three-dimensional printed PLA scaffold and human gingival stem cell-derived extracellular vesicles: A new tool for bone defect repair. Stem Cell Res Ther. 2018;9(1):104-018-0850-0. doi: 10.1186/s13287-018-0850-0 [doi].

33. Gudbergsson JM, Johnsen KB, Skov MN, Duroux M. Systematic review of factors influencing extracellular vesicle yield from cell cultures. Cytotechnology. 2016;68(4):579-592. doi: 10.1007/s10616-015-9913-6 [doi].

34. Witwer KW, Buzas EI, Bemis LT, et al. Standardization of sample collection, isolation and analysis methods in extracellular vesicle research. $J$ Extracell Vesicles. 2013;2:10.3402/jev.v2i0.20360. eCollection 2013. doi: 10.3402/jev.v2i0.20360 [doi].

35. Yamashita T, Takahashi Y, Takakura Y. Possibility of exosome-based therapeutics and challenges in production of exosomes eligible for therapeutic application. Biol Pharm Bull. 2018;41(6):835-842. doi: 10.1248/bpb.b18-00133 [doi].

36. Lai RC, Yeo RW, Tan KH, Lim SK. Exosomes for drug delivery - a novel application for the mesenchymal stem cell. Biotechnol Adv. 2013;31(5):543-551. doi: 10.1016/j.biotechadv.2012.08.008 [doi]. 
37. Nilsson J, Skog J, Nordstrand A, et al. Prostate cancer-derived urine exosomes: A novel approach to biomarkers for prostate cancer. Br J Cancer. 2009;100(10):1603-1607. doi: 10.1038/sj.bjc.6605058 [doi].

38. Baran J, Baj-Krzyworzeka M, Weglarczyk K, et al. Circulating tumour-derived microvesicles in plasma of gastric cancer patients. Cancer Immunol Immunother. 2010;59(6):841-850. doi: 10.1007/s00262-009-0808-2 [doi].

39. Huttner HB, Janich P, Kohrmann M, et al. The stem cell marker prominin-1/CD133 on membrane particles in human cerebrospinal fluid offers novel approaches for studying central nervous system disease. Stem Cells. 2008;26(3):698-705. doi: 2007-0639 [pii].

40. Nawaz M, Camussi G, Valadi H, et al. The emerging role of extracellular vesicles as biomarkers for urogenital cancers. Nat Rev Urol. 2014;11(12):688-701. doi: 10.1038/nrurol.2014.301 [doi].

41. Roy S, Hochberg FH, Jones PS. Extracellular vesicles: The growth as diagnostics and therapeutics; a survey. J Extracell Vesicles. 2018;7(1):1438720. doi:

10.1080/20013078.2018.1438720 [doi].

42. Escudier B, Dorval T, Chaput N, et al. Vaccination of metastatic melanoma patients with autologous dendritic cell (DC) derived-exosomes: Results of thefirst phase I clinical trial. J Transl Med. 2005;3(1):10-5876-3-10. doi: 1479-5876-3-10 [pii].

43. Morse MA, Garst J, Osada T, et al. A phase I study of dexosome immunotherapy in patients with advanced non-small cell lung cancer. J Transl Med. 2005;3(1):9-5876-3-9. doi: 1479-5876-3-9 [pii]. 
44. Dai S, Wei D, Wu Z, et al. Phase I clinical trial of autologous ascites-derived exosomes combined with GM-CSF for colorectal cancer. Mol Ther. 2008;16(4):782-790. doi: 10.1038/mt.2008.1 [doi].

45. Besse B, Charrier M, Lapierre V, et al. Dendritic cell-derived exosomes as maintenance immunotherapy after first line chemotherapy in NSCLC. Oncoimmunology. 2015;5(4):e1071008. doi: 10.1080/2162402X.2015.1071008 [doi].

46. Kordelas L, Rebmann V, Ludwig AK, et al. MSC-derived exosomes: A novel tool to treat therapy-refractory graft-versus-host disease. Leukemia. 2014;28(4):970-973. doi: 10.1038/leu.2014.41 [doi].

47. Gimona M, Pachler K, Laner-Plamberger S, Schallmoser K, Rohde E. Manufacturing of human extracellular vesicle-based therapeutics for clinical use. Int J Mol Sci. 2017;18(6):10.3390/ijms18061190. doi: E1190 [pii].

48. Willis GR, Fernandez-Gonzalez A, Anastas J, et al. Mesenchymal stromal cell exosomes ameliorate experimental bronchopulmonary dysplasia and restore lung function through macrophage immunomodulation. Am J Respir Crit Care Med. 2018;197(1):104-116. doi: 10.1164/rccm.201705-0925OC [doi].

49. Lee C, Mitsialis SA, Aslam M, et al. Exosomes mediate the cytoprotective action of mesenchymal stromal cells on hypoxia-induced pulmonary hypertension. Circulation. 2012;126(22):2601-2611. doi: 10.1161/CIRCULATIONAHA.112.114173 [doi].

50. Aliotta JM, Pereira M, Wen S, et al. Exosomes induce and reverse monocrotaline-induced pulmonary hypertension in mice. Cardiovasc Res. 2016;110(3):319-330. doi: 10.1093/cvr/cvw054 [doi]. 
51. Zhu YG, Feng XM, Abbott J, et al. Human mesenchymal stem cell microvesicles for treatment of escherichia coli endotoxin-induced acute lung injury in mice. Stem Cells. 2014;32(1):116-125. doi: 10.1002/stem.1504 [doi].

52. Monsel A, Zhu YG, Gennai S, et al. Therapeutic effects of human mesenchymal stem cellderived microvesicles in severe pneumonia in mice. Am J Respir Crit Care Med. 2015;192(3):324336. doi: 10.1164/rcem.201410-1765OC [doi].

53. Yu B, Kim HW, Gong M, et al. Exosomes secreted from GATA-4 overexpressing mesenchymal stem cells serve as a reservoir of anti-apoptotic microRNAs for cardioprotection. Int J Cardiol. 2015;182:349-360. doi: 10.1016/j.ijcard.2014.12.043 [doi].

54. Teng X, Chen L, Chen W, Yang J, Yang Z, Shen Z. Mesenchymal stem cell-derived exosomes improve the microenvironment of infarcted myocardium contributing to angiogenesis and antiinflammation. Cell Physiol Biochem. 2015;37(6):2415-2424. doi: 10.1159/000438594 [doi].

55. Bian S, Zhang L, Duan L, Wang X, Min Y, Yu H. Extracellular vesicles derived from human bone marrow mesenchymal stem cells promote angiogenesis in a rat myocardial infarction model. $J$ Mol Med (Berl). 2014;92(4):387-397. doi: 10.1007/s00109-013-1110-5 [doi].

56. Lai RC, Arslan F, Lee MM, et al. Exosome secreted by MSC reduces myocardial ischemia/reperfusion injury. Stem Cell Res. 2010;4(3):214-222. doi: 10.1016/j.scr.2009.12.003 [doi].

57. Arslan F, Lai RC, Smeets MB, et al. Mesenchymal stem cell-derived exosomes increase ATP levels, decrease oxidative stress and activate PI3K/akt pathway to enhance myocardial viability and prevent adverse remodeling after myocardial ischemia/reperfusion injury. Stem Cell Res. 2013;10(3):301-312. doi: 10.1016/j.scr.2013.01.002 [doi]. 
58. Kim DK, Nishida H, An SY, Shetty AK, Bartosh TJ, Prockop DJ. Chromatographically isolated CD63+CD81+ extracellular vesicles from mesenchymal stromal cells rescue cognitive impairments after TBI. Proc Natl Acad Sci U S A. 2016;113(1):170-175. doi: 10.1073/pnas.1522297113 [doi].

59. Yu B, Shao H, Su C, et al. Exosomes derived from MSCs ameliorate retinal laser injury partially by inhibition of MCP-1. Sci Rep. 2016;6:34562. doi: 10.1038/srep34562 [doi].

60. Mead B, Tomarev S. Bone marrow-derived mesenchymal stem cells-derived exosomes promote survival of retinal ganglion cells through miRNA-dependent mechanisms. Stem Cells Transl Med. 2017;6(4):1273-1285. doi: 10.1002/sctm.16-0428 [doi].

61. Doeppner TR, Herz J, Gorgens A, et al. Extracellular vesicles improve post-stroke neuroregeneration and prevent postischemic immunosuppression. Stem Cells Transl Med. 2015;4(10):1131-1143. doi: 10.5966/sctm.2015-0078 [doi].

62. Xin H, Li Y, Cui Y, Yang JJ, Zhang ZG, Chopp M. Systemic administration of exosomes released from mesenchymal stromal cells promote functional recovery and neurovascular plasticity after stroke in rats. J Cereb Blood Flow Metab. 2013;33(11):1711-1715. doi: 10.1038/jcbfm.2013.152 [doi].

63. Lo Sicco C, Reverberi D, Balbi C, et al. Mesenchymal stem cell-derived extracellular vesicles as mediators of anti-inflammatory effects: Endorsement of macrophage polarization. Stem Cells Transl Med. 2017;6(3):1018-1028. doi: 10.1002/sctm.16-0363 [doi].

64. Tan CY, Lai RC, Wong W, Dan YY, Lim SK, Ho HK. Mesenchymal stem cell-derived exosomes promote hepatic regeneration in drug-induced liver injury models. Stem Cell Res Ther. 2014;5(3):76. doi: 10.1186/scrt465 [doi]. 
65. Li T, Yan Y, Wang B, et al. Exosomes derived from human umbilical cord mesenchymal stem cells alleviate liver fibrosis. Stem Cells Dev. 2013;22(6):845-854. doi: 10.1089/scd.2012.0395 [doi].

66. Yang J, Liu XX, Fan H, et al. Extracellular vesicles derived from bone marrow mesenchymal stem cells protect against experimental colitis via attenuating colon inflammation, oxidative stress and apoptosis. PLoS One. 2015;10(10):e0140551. doi: 10.1371/journal.pone.0140551 [doi].

67. Fang S, Xu C, Zhang Y, et al. Umbilical cord-derived mesenchymal stem cell-derived exosomal MicroRNAs suppress myofibroblast differentiation by inhibiting the transforming growth factorbeta/SMAD2 pathway during wound healing. Stem Cells Transl Med. 2016;5(10):1425-1439. doi: sctm.2015-0367 [pii].

68. Zhang J, Guan J, Niu X, et al. Exosomes released from human induced pluripotent stem cellsderived MSCs facilitate cutaneous wound healing by promoting collagen synthesis and angiogenesis. J Transl Med. 2015;13:49-015-0417-0. doi: 10.1186/s12967-015-0417-0 [doi].

69. Zou X, Zhang G, Cheng Z, et al. Microvesicles derived from human wharton's jelly mesenchymal stromal cells ameliorate renal ischemia-reperfusion injury in rats by suppressing CX3CL1. Stem Cell Res Ther. 2014;5(2):40. doi: 10.1186/scrt428 [doi].

70. Bruno S, Grange C, Collino F, et al. Microvesicles derived from mesenchymal stem cells enhance survival in a lethal model of acute kidney injury. PLoS One. 2012;7(3):e33115. doi: 10.1371/journal.pone.0033115 [doi].

71. Tao SC, Yuan T, Zhang YL, Yin WJ, Guo SC, Zhang CQ. Exosomes derived from miR-1405p-overexpressing human synovial mesenchymal stem cells enhance cartilage tissue regeneration and prevent osteoarthritis of the knee in a rat model. Theranostics. 2017;7(1):180-195. doi: 10.7150/thno.17133 [doi]. 
72. Furuta T, Miyaki S, Ishitobi H, et al. Mesenchymal stem cell-derived exosomes promote fracture healing in a mouse model. Stem Cells Transl Med. 2016;5(12):1620-1630. doi: sctm.20150285 [pii].

73. Cosenza S, Ruiz M, Toupet K, Jorgensen C, Noel D. Mesenchymal stem cells derived exosomes and microparticles protect cartilage and bone from degradation in osteoarthritis. Sci Rep. 2017;7(1):16214-017-15376-8. doi: 10.1038/s41598-017-15376-8 [doi].

74. Rhys HI, Dell'Accio F, Pitzalis C, Moore A, Norling LV, Perretti M. Neutrophil microvesicles from healthy control and rheumatoid arthritis patients prevent the inflammatory activation of macrophages. EBioMedicine. 2018;29:60-69. doi: S2352-3964(18)30052-5 [pii].

75. Headland SE, Jones HR, Norling LV, et al. Neutrophil-derived microvesicles enter cartilage and protect the joint in inflammatory arthritis. Sci Transl Med. 2015;7(315):315ra190. doi: 10.1126/scitranslmed.aac5608 [doi].

76. Cui Y, Luan J, Li H, Zhou X, Han J. Exosomes derived from mineralizing osteoblasts promote ST2 cell osteogenic differentiation by alteration of microRNA expression. FEBS Lett. 2016;590(1):185-192. doi: 10.1002/1873-3468.12024 [doi].

77. Ekstrom K, Omar O, Graneli C, Wang X, Vazirisani F, Thomsen P. Monocyte exosomes stimulate the osteogenic gene expression of mesenchymal stem cells. PLoS One. 2013;8(9):e75227. doi: 10.1371/journal.pone.0075227 [doi].

78. Silva AM, Almeida MI, Teixeira JH, et al. Dendritic cell-derived extracellular vesicles mediate mesenchymal stem/stromal cell recruitment. Sci Rep. 2017;7(1):1667-017-01809-x. doi: 10.1038/s41598-017-01809-x [doi]. 
